\title{
EVALUASI KEGIATAN PRESERVASI FISIK NASKAH KUNO DI PERPUSTAKAAN NASIONAL RI MENGGUNAKAN MODEL CIPP (CONTEXT, INPUT, PROCESS, PRODUCT)
}

\author{
Ratnawati Nurwahyuningsih ${ }^{1^{*}}$; Nita Ismayati ${ }^{2^{*}}$ \\ ${ }^{1}$ Perpustakaan Nasional RI \\ ${ }^{2}$ Universitas YARSI \\ *Korespondensi: ratnawati_nurwahyuningsih@perpusnas.go.id; n.ismayati@yarsi.ac.id
}

\begin{abstract}
ABSTRAK
Naskah kuno menjadi salah satu sumber informasi yang memiliki nilai-nilai luhur dan dapat menjadi pedoman untuk peningkatan kecerdasan intelektual, spiritual dan emosional bangsa Indonesia. Jumlah naskah kuno yang terdapat di Perpustakaan Nasional RI sebanyak 11.147 naskah. Koleksi terbuat dari kertas, lontar, bambu, kulit kayu, dan rotan yang berasal dari berbagai daerah di seluruh nusantara ditulis dengan aksara dan bahasa daerah. Hasil studi dokumentasi menunjukkan bahwa tingkat kerusakan naskah kuno terus meningkat. Tahun 1989 kondisi kerusakan naskah kuno sebesar 17\%, tahun 2004 menjadi 46,3\% dan tahun 2013 menjadi 56,21\%. Berbagai upaya preservasi naskah kuno telah dilakuk an. Tujuan penelitian ini untuk melakukan evaluasi terhadap kegiatan preservasi fisik naskah kuno di Perpustakaan Nasional RI menggunakan model CIPP (Context, Input, Process, Product). Metode penelitian menggunakan kualitatif. Teknik pengambilan sampel menggunakan sample purposive. Pengumpulan data dilakukan dengan observasi, studi dokumentasi dan wawancara. Wawancara dilakukan kepada informan yang mengetahui kegiatan preservasi fisik naskah kuno sebanyak 5 orang. Hasil penelitian menggambarkan bahwa kegiatan preservasi fisik sudah berjalan namun dalam pelaksanaannya masih kurang maksimal, karena belum adanya kebijakan nasional dan standard bidang pelestarian naskah kuno, kurangnya ketrampilan SDM, sarana dan prasarana, serta anggaran, belum adanya jabatan fungsional konseravator. Pengesahan kebijakan nasional pelestarian naskah dan pembuatan standar pelestarian naskah di Indonesia merupakan rekomendasi penelitian ini.
\end{abstract}

Kata kunci: preservasi naskah kuno; evaluasi preservasi; model CIPP; Perpustakaan Nasional RI

\section{PENDAHULUAN}

Koleksi naskah kuno merupakan koleksi unggulan dan langka yang jarang ditemukan di perpustakaan lain. Naskah kuno juga menjadi favorit di Perpustakaan Nasional RI karena kekhasan yang dimilikinya. Naskah kuno yang ditulis dengan tangan dan tidak ada copy (duplikatnya) membuat koleksi ini unik. Naskah kuno menjadi salah satu sumber informasi yang memiliki nilai-nilai luhur dan dapat menjadi pedoman untuk peningkatan kecerdasan intelektual, spiritual dan emosional bangsa Indonesia. Naskah kuno yang ditulis dengan berbagai bahasa dan aksara ini perlu diselamatkan dan dijaga kelestariannya. 
Menurut Undang-undang nomor 43 tahun 2007 tentang Perpustakaan, naskah kuno adalah semua dokumen tertulis yang tidak dicetak atau tidak diperbanyak dengan cara lain, baik yang berada di dalam negeri maupun luar negeri yang berumur sekurang-kurangn ya 50 (lima puluh) tahun dan yang mempunyai nilai penting bagi kebudayaan nasional, sejarah dan ilmu pengetahuan (pasal 1 ayat 4). Naskah kuno dianggap penting bagi kemajuan bangsa Indonesia. Oleh karena itu, terdapat peraturan dan undang-undang yang dibuat untuk menjaga kelestariannya. Peraturan tersebut menyangkut tentang tugas, tanggung jawab, kewajiban, dan kewenangan dari Pemerintah Pusat (Perpustakaan Nasional RI), Pemerintah Daerah, dan masyarakat penggiat pelestarian.

Perpustakaan Nasional RI memiliki beberapa tugas, diantaranya adalah sebagai deposit terbitan nasional, rujukan dan pelestarian hasil budaya bangsa. Untuk memudahkan pengumpulan dan menjamin kelengkapan deposit terbitan, telah diterbitkan Undang-Undang No.4 tahun 1990 tentang Wajib Serah Simpan Karya Cetak dan Karya Rekam. Selain itu Perpustakaan Nasional RI juga mempunyai kewajiban dalam pelestarian sesuai yang diamanatkan oleh Undang-Undang No.43 tahun 2007. Pada pasal 7 ayat 1 butir d, yaitu Pemerintah wajib menjamin ketersediaan keragaman koleksi perpustakaan melalui terjemahan (translasi), alih aksara (tranliterasi), alih suara ke tulisan (transkripsi), dan alih media (transmedia).

Jumlah naskah kuno yang terdapat di Perpustakaan Nasional RI sebanyak 11.147 naskah. Koleksi ini berupa kertas, lontar, bambu, kulit kayu dan rotan. Naskah ini berasal dari berbagai daerah di seluruh nusantara yang ditulis menggunakan aksara dan bahasa daerah. Pengumpulan naskah kuno ini sudah dilakukan sejak zaman kolonial Belanda, yaitu sejak berdirinya Bataviaasch Genootschap van Kunsten en Wetenschappen (BG) tahun 1778 dan mulai melakukan pengadaan tahun 1845. Mulai tahun 1923 BG berubah menjadi Koninklijk Bataviaasch Genootschap (KGB). Setelah Indonesia merdeka KGB berganti nama menjadi Lembaga Budaya Indonesia dan akhirnya menjadi Museum Nasional. Pada tahun 1989 Museum Nasional menyerahkan naskah kuno ke Perpustakaan Nasional RI. Saat ini pengadaan naskah kuno dilakukan melalui pembelian dari dana APBN, hibah, hadiah atau titipan. 
The International Review Team for Conservation and Preservation (IRT) melakukan survey kondisi naskah kuno di Perpustakaan Nasional RI tahun 1989. Latar belakang dilakukannya survey tersebut adalah bahwa koleksi buku, majalah, koran, dan naskah kuno/manuskrip yang ada di Perpustakaan Nasional adalah koleksi terbaik di Indonesia. Untuk itu, perlu dilakukan penelitian untuk membantu perpustakaan nasional dalam memenuhi tugas menghadapi tantangan pelestarian. Hasil survey menunjukkan bahwa naskah kuno sebanyak 17\% dalam kondisi rusak. Naskah kuno yang diteliti sebanyak 1521 naskah kuno.

Selanjutnya, pada tahun 2004, penelitian lanjutan tentang kerusakan naskah kuno di Perpustakaan Nasional juga dilakukan oleh Muhammadin Razak. Penelitian ini untuk menindaklanjuti rekomendasi dari The International Riview Team for Conservation and Preservation. Tujuan penelitian adalah:

1. Mendapatkan data tentang jumlah koleksi manuskrip terjilid yang dimiliki oleh Perpustakaan Nasional RI, bagaimana kondisi fisik manuskrip dan bentuk mikronya serta kondisi lingkungan tempat penyimpanan manuskrip tersebut.

2. Mendapatkan data tentang pelaksanaan pelestarian manuskrip, baik konservasi preventif, konservasi pasif maupun konservasi aktif

3. Mengkaji kebijakan pelestarian dari negara-negara yang sudah maju dari berbagai sumber untuk menyusun kebijakan pelestarian manuskrip yang akan direkomendasikan kepada Perpustakaan Nasional RI. Hasil penelitiannya menunjukkan bahwa kondisi naskah kuno yang rusak meningkat menjadi $46,3 \%$.

Tahun 2013 jumlah naskah kuno yang rusak di Perpustakaan Nasional meningkat lagi menjadi 56,21\%. Hal ini berdasarkan laporan hasil pemetaan survei kondisi koleksi Perpustakaan Nasional tahun 2013 sebagaimana terlihat pada tabel 1.

Tabel 1. Jenis Dan Jumlah Kerusakan Koleksi Perpustakaan Nasional RI Tahun 2013

\begin{tabular}{|c|l|c|c|c|c|c|c|c|}
\hline \multirow{2}{*}{ No. } & \multirow{2}{*}{$\begin{array}{c}\text { Jenis } \\
\text { Koleksi }\end{array}$} & \multirow{2}{*}{$\begin{array}{c}\text { Jumlah/ } \\
\text { Eks }\end{array}$} & \multicolumn{2}{|c|}{ Kondisi Baik } & \multicolumn{2}{c|}{ Kondisi Sedang } & \multicolumn{2}{c|}{ Kondisi Rusak } \\
\cline { 4 - 9 } & & $\mathbf{\%}$ & Eks & \% & Eks & \% & Eks \\
\hline 1. & Buku Langka & 120.222 & 2.01 & 2.525 & 4,12 & 4.953 & 93.87 & 112.744 \\
\hline 2. & $\begin{array}{l}\text { Majalah } \\
\text { langka }\end{array}$ & 80.400 & 13.39 & 10.765 & 7.88 & 6.335 & 78.73 & 63.300 \\
\hline 3. & $\begin{array}{l}\text { Surat kabar } \\
\text { langka }\end{array}$ & 126.057 & 12.08 & 15.227 & 11,22 & 14.143 & 76.7 & 96.687 \\
\hline 4. & Naskah kuno & $\mathbf{1 0 . 1 6 3}$ & $\mathbf{2 1 . 0 8}$ & $\mathbf{2 . 1 4 2}$ & $\mathbf{2 2 . 7 1}$ & $\mathbf{2 . 3 0 8}$ & $\mathbf{5 6 . 2 1}$ & $\mathbf{5 . 7 1 3}$ \\
\hline 5. & Peta/Lukisan & 35.530 & 44,43 & 15.785 & 18,97 & 6.740 & 36,6 & 13.004 \\
\hline
\end{tabular}


Bibliotech : Jurnal Ilmu Perpustakaan dan Informasi, 4 (1) 2019

\begin{tabular}{|c|l|c|c|c|c|c|c|c|}
\hline \multirow{2}{*}{ No. } & \multirow{2}{*}{$\begin{array}{c}\text { Jenis } \\
\text { Koleksi }\end{array}$} & \multirow{2}{*}{$\begin{array}{c}\text { Jumlah/ } \\
\text { Eks }\end{array}$} & \multicolumn{2}{|c|}{ Kondisi Baik } & \multicolumn{2}{c|}{ Kondisi Sedang } & \multicolumn{2}{c|}{ Kondisi Rusak } \\
\cline { 4 - 9 } & & \% & Eks & $\%$ & Eks & $\%$ & Eks \\
\hline 6. & $\begin{array}{l}\text { Koleksi } \\
\text { Audio } \\
\text { vis/Audio } \\
\text { Visuall }\end{array}$ & 63.142 & 69.06 & 43.605 & 21,84 & 13.790 & 9.1 & 5.747 \\
\hline TOTAL & $\begin{array}{c}435.514 \\
\text { eks. }\end{array}$ & $27 \%$ & 91.300 & $15 \%$ & 48.271 & $58 \%$ & 387.514 \\
\hline
\end{tabular}

(Sumber : Laporan survei kondisi koleksi Perpustakaan Nasional RI, tahun 2013)

Ketiga penelitian tersebut menunjukkan bahwa terdapat kenaikan tingkat kerusakan naskah kuno yang berada di Perpustakaan Nasional RI. Pada tahun 1989 kondisi kerusakan sebesar 17\%, meningkat pada tahun 2004 menjadi 46,3\%. Terakhir pada tahun 2013 meningkat menjadi $56,21 \%$.

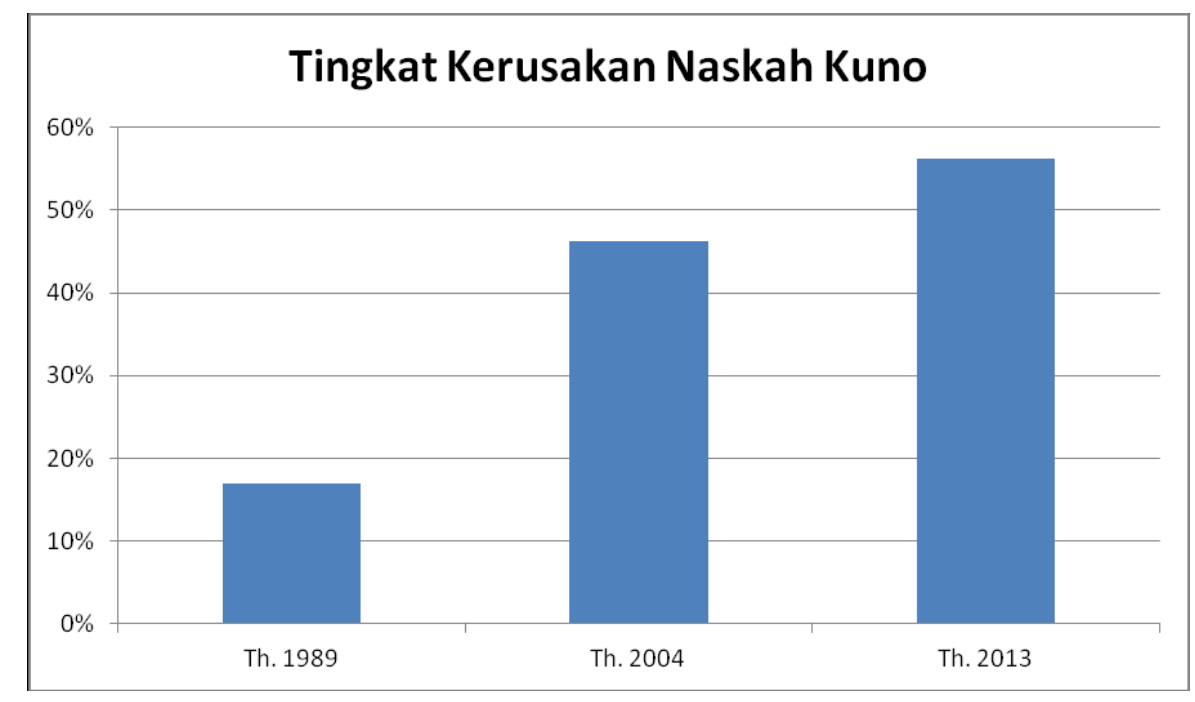

Gambar 1. Tingkat Kerusakan Naskah Kuno

Meningkatnya jumlah naskah kuno yang rusak di Perpustakaan Nasional RI menjadi suatu keprihatinan tersendiri karena Perpustakaan Nasional RI yang fungsin ya sebagai perpustakaan deposit dan menjadi pembina pelestarian bagi lembaga perpustakaan lain mengalami kenyataan bahwa koleksi naskah kuno yang disimpannya semakin tinggi tingkat kerusakannya dari tahun ke tahun. Di Perpustakaan Nasional RI sudah dibentuk Unit Preservasi Bahan Pustaka yang mempunyai fungsi utama yaitu merumuskan dan melaksanakan kebijakan pelestarian pustaka hasil karya bangsa dan dapat menjadi pedoman dan acuan bagi semua lembaga perpustakaan di 
Indonesia. Melalui kegiatan pelestarian, maka usia pakai bahan perpustakaan akan menjadi lebih panjang dan hasil akhir kegiatan pelestarian dapat digunakan sebagai sumber informasi yang sama dengan bentuk aslinya.

Namun demikian, mengapa tingkat kerusakan naskah kuno yang disimpan di Perpustakaan Nasional RI semakin meningkat. Hal itulah yang mendorong peneliti untuk melakukan penelitian terkait hal tersebut dengan melakukan evaluasi terhadap kegiatan preservasi dan konservasi yang dilakukan di Perpustakaan Nasional RI. Evaluasi menggunakan model evaluasi CIPP (Context, Input, Process, Product).

\section{METODE}

Penelitian ini merupakan penelitian kualitatif dengan sampel purposive. Teknik pengumpulan data menggunakan observasi, wawancara, dan studi dokumentasi. Proses pengumpulan dan analisis data mengacu pada model evaluasi CIPP (Context, Input, Process, Product) dari Sufflebeam (2012). Setiap pertanyaan dari setiap tahapan evaluasi dicari ke tiga sumber data, yaitu melalui observasi, wawancara, dan studi dokumentasi. Proses pengumpulan data dilakukan sebagai berikut :

1. Observasi dilakukan dengan cara pengamatan langsung terhadap kegiatan preservasi naskah kuno di Perpustakaan Nasional RI.

2. Wawancara dilakukan melalui tatap muka langsung dengan informan dan menggunakan alat perekam, agar hasil wawancara yang diperoleh dapat terjaga keakuratannya dan sewaktu-waktu apabila wawancara dibutuhkan lagi dapat diputar kembali. Wawancara dilakukan kepada 5 orang yaitu 4 orang dari Pusat Preservasi dan 1 orang diari bagian naskah kuno sebagaimana di tabel 2 berikut :

Tabel 2. Data Informan

\begin{tabular}{|l|l|l|}
\hline No & \multicolumn{1}{|c|}{ Jabatan } & \multicolumn{1}{c|}{ Tugas/Deskripsi Kerja } \\
\hline 1 & Kepala Pusat Preservasi BP & $\begin{array}{l}\text { Melaksanakan pelestarian kandungan } \\
\text { informasi dan fisik bahan pustaka }\end{array}$ \\
\hline 2 & Kepala Bidang Konservasi & $\begin{array}{l}\text { Melaksanakan pelestarian fisik melalui } \\
\text { pemeliharaan, perawatan, perbaikan restorasi, } \\
\text { dan penjilidan bahan pustaka }\end{array}$ \\
\hline
\end{tabular}


Bibliotech : Jurnal Ilmu Perpustakaan dan Informasi, 4 (1) 2019

\begin{tabular}{|l|l|l|}
\hline No & \multicolumn{1}{|c|}{ Jabatan } & \multicolumn{1}{|c|}{ Tugas/Deskripsi Kerja } \\
\hline 3 & $\begin{array}{l}\text { Kepala Sub Bidang } \\
\text { Perawatan dan Perbaikan BP }\end{array}$ & $\begin{array}{l}\text { Melaksanakan penelitian dan pelaksanaan } \\
\text { teknis konservasi dalam kegiatan perawatan, } \\
\text { perbaikan dan pengawetan bahan pustaka }\end{array}$ \\
\hline 4 & Staf & Melaksanakan kegiatan teknis konservasi \\
\hline 5 & $\begin{array}{l}\text { Kepala Bidang Layanan } \\
\text { Koleksi Khusus }\end{array}$ & Melaksanakan tugas layanan koleksi khusus \\
\hline
\end{tabular}

3. Studi Dokumentasi dengan menggali informasi yang bersumber pada pedoman, panduan, dan standar tentang evaluasi di bidang preservasi naskah kuno.

Metode Triangulasi sebagai proses validasi data dilakukan terhadap sumber data yang diperoleh dari tiga instrumen yang digunakan. Selanjutnya, data dianalisis dengan tahapan reduksi data, penyajian data, dan penarikan kesimpulan.

\section{HASIL DAN PEMBAHASAN}

Dalam proses pengumpulan data, pertama ditentukan lebih dahulu apa saja hal-hal yang akan diajukan dalam setiap tahapan evaluasi dari model CIPP. Terdapat empat tahapan evaluasi dalam model CIPP. Berikut penjabarannya:

1. Evaluasi konteks (Context) mencakup tujuan kegiatan, konteks kegiatan, kebijakan/standar preservasi, dan evaluasi kegiatan.

2. Evaluasi masukan (Input) mencakup evaluasi terhadap pedoman atau standar, pelaksanaan kegiatan, mekanisme kerja preservasi Sumber Daya Manusia (SDM), sarana dan prasarana, dan anggaran.

3. Evaluasi Proses (Process) mencakup evaluasi terhadap penerapan rekomendasi IRT, kegiatan yang dilaksanakan, fungsi pembinaan pelestarian, kerjasama, strategi pelestarian, jadwal kegiatan, penanggung jawab kegiatan, serta kapan kegiatan selesai dan hambatan yang dihadapi dalam melakukan pelestarian.

4. Evaluasi produk (Product) mencakup evaluasi terhadap output, outcome, kesesuaian kegiatan dengan standar, dan keberlanjutan program pelestarian.

\section{Evaluasi Konteks (Context)}

Evaluasi Konteks merupakan evaluasi terhadap keadaan atau kegiatan preservasi itu sendiri, menyajikan data mengenai alasan untuk menetapkan tujuan kegiatan dan prioritas tujuan. 
Hasil temuan dan Analisis evaluasi konteks yang diperoleh dalam kegiatan preservasi fisik naskah kuno di Perpustakaan Nasional RI dapat dilihat di tabel 3 sebagai berikut:

Tabel 3. Hasil temuan dan Analisis Evaluasi Konteks (Contex)

\begin{tabular}{|c|c|c|}
\hline \multicolumn{3}{|r|}{ Evaluasi Konteks } \\
\hline 1 & a. Tujuan Kegiatan & $\begin{array}{l}\text { Melestarikan fisik bahan perpustakaan dan kandungan } \\
\text { informasinya agar dapat dimanfaatkan oleh masyarakat }\end{array}$ \\
\hline & $\begin{array}{l}\text { b. Analisis Tujuan } \\
\text { Kegiatan }\end{array}$ & $\begin{array}{l}\text { Berdasarkan hasil penelitian tujuan kegiatan sudah } \\
\text { terlaksana dengan baik, Pusat Preservasi Bahan Pustaka } \\
\text { telah melakukan kegiatan perawatan dan perbaikan } \\
\text { naskah kuno sesuai dengan tujuan kegiatan. Tetapi tujuan } \\
\text { preservasi belum tercapai sesuai dengan sasaran kegiatan. }\end{array}$ \\
\hline \multirow[t]{2}{*}{2} & a. Konteks Kegiatan & Preservasi fisik naskah kuno (Konservasi naskah) \\
\hline & $\begin{array}{l}\text { b. Analisis Konteks } \\
\text { Kegiatan }\end{array}$ & $\begin{array}{l}\text { Konteks kegiatan sudah terlaksana dengan baik tetapi } \\
\text { masih perlu peningkatan untuk sarana dan prasarana, } \\
\text { SDM, standar nasional preservasi dan anggaran }\end{array}$ \\
\hline \multirow[t]{2}{*}{3} & $\begin{array}{l}\text { a. Kebijakan Bidang } \\
\text { Preservasi }\end{array}$ & $\begin{array}{l}\text { Kebijakan bidang preservasi yang dipakai sudah mengacu } \\
\text { pada standar internasional dan kebijakan yang berlaku di } \\
\text { gunakan di lingkungan Perpustakaan Nasional RI }\end{array}$ \\
\hline & $\begin{array}{l}\text { b. Analisis Kebijakan } \\
\text { Bidang Preservasi }\end{array}$ & Belum ada kebijakan nasional bidang preservasi \\
\hline \multirow[t]{2}{*}{4} & a. Evaluasi kegiatan & $\begin{array}{l}\text { Evaluasi terhadap perservasi sudah dilakukan dengan } \\
\text { rapat internal, pembuatan Laporan Evaluasi dan } \\
\text { Penyusunan LKIP Pusat Preservasi Bahan Pustaka }\end{array}$ \\
\hline & $\begin{array}{l}\text { b. Analisis } \\
\text { kegiatan }\end{array}$ & $\begin{array}{l}\text { Evaluasi preservasi telah dilaksanakan oleh Pusat } \\
\text { Preservasi dan dilakukan secara berkala. }\end{array}$ \\
\hline
\end{tabular}

Dinilai dari tujuan dari kegiatan preservasi sudah relevan dengan sasaran programnya. Sasaran programnya adalah naskah kuno yang sudah rusak/rapuh. Tetapi tujuan dari kegiatan preservasi naskah kuno ini belum tercapai sepenuhnya karena banyaknya naskah kuno yang belum terkonservasi, seperti yang diungkapkan oleh Kepala Pusat Preservasi Bahan Pustaka berikut " belum tercapai karena baru $11 \%$ naskah kuno dari 56,21 persen naskah kuno di Perpustakaan nasional RI yang kondisinya rusak berat dilakukan konservasi dan dilakukan digitalisasi."

Bahkan, dilihat dari target jumlah naskah kuno yang dipreservasi hanya 10 eksemplar per tahun, akan memerlukan waktu yang lama untuk konservasi semua naskah kuno yang rusak. Dari segi kebutuhan untuk mencapai tujuan program masih banyak yang belum terpenuhi di antaranya jumlah dan kompetensi sumber daya manusia, anggaran, sarana dan prasarana, dan standar nasional preservasi. Dilihat dari segi kebijakan, kegiatan pelestarian ini belum mempunyai 
kebijakan nasional bidang preservasi tetapi hanya memakai kebijakan preservasi yang ada di lingkungan Perpustakaan Nasional RI saja.

\section{Evaluasi Masukan (Input)}

Evaluasi Input ini membahas tentang pedoman/standart pelaksanaan kegiatan, mekanisme kerja preservasi, SDM, sarana dan prasarana, anggaran. Hasil temuan dan analisis evaluasi masukan (input) pada kegiatan preservasi fisik naskah kuno di Perpustakaan Nasional RI sebagai berikut :

Tabel 4. Hasil Temuan dan Analisis Evaluasi Masukan (Input)

\begin{tabular}{|c|c|c|}
\hline \multicolumn{3}{|c|}{ Evaluasi Input } \\
\hline 1 & $\begin{array}{l}\text { a. Pedoman/standar pelaksanaan } \\
\text { kegiatan preservasi naskah kuno }\end{array}$ & $\begin{array}{l}\text { Pedoman/standar pelaksanaan kegiatan preservasi } \\
\text { naskah kuno telah dibuat oleh Pusat Preservasi } \\
\text { Bahan Pustaka }\end{array}$ \\
\hline & $\begin{array}{l}\text { b. Analisis } \quad \text { Pedoman } / \text { standar } \\
\text { pelaksanaan kegiatan preservasi } \\
\text { naskah kuno }\end{array}$ & $\begin{array}{l}\text { Pedoman/standar yang dibuat merupakan acuan } \\
\text { untuk kegiatan preservasi bahan pustaka }\end{array}$ \\
\hline \multirow[t]{2}{*}{2} & a. Mekanisme kerja preservasi & $\begin{array}{l}\text { Mekanisme kerja preservasi antara kewenangan } \\
\text { pusat dan daerah diatur dalam PP no. } 13 \text { tahun } 2014 . \\
\text { Pada pasal } 10 \text { disebutkan bahwa pemerintah daerah } \\
\text { mempunyai kewenangan mengalihmediakan naskah } \\
\text { kuno yang dimiliki oleh masyarakat di wilayah } \\
\text { masing-masing untuk dilestarikan dan di } \\
\text { dayagunakan. }\end{array}$ \\
\hline & 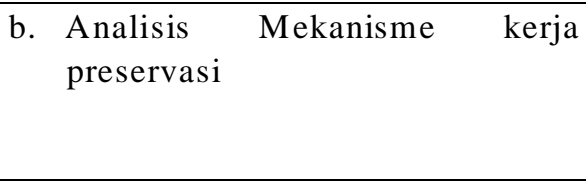 & $\begin{array}{l}\text { Mekanisme kerja preservasi antara pusat dan daerah } \\
\text { sudah ada, tetapi pelaksanaannya di daerah tidak } \\
\text { berjalan karena kurangnya SDM, sarana dan } \\
\text { prasarana dan anggaran }\end{array}$ \\
\hline \multirow[t]{2}{*}{3} & a. SDM & $\begin{array}{l}\text { Latar belakang SDM sesuai dengan bidangnya } \\
\text { sebanyak } 75 \% \text {, Ketrampilan SDM dalam } \\
\text { pelaksanaan kegiatan masih kurang, magang dan } \\
\text { diklat belum terprogram, belum adanya jabatan } \\
\text { fungsional konservator, sosialisasi preservasi } \\
\text { dilaksanakan setiap tahun, kampanye/promosi tidak } \\
\text { dilakukan berkala }\end{array}$ \\
\hline & b. Analisis SDM & $\begin{array}{l}\text { Ketrampilan SDM kurang memadai perlu } \\
\text { peningkatan SDM melalui magang kerja, workshop, } \\
\text { studi banding. Magang kerja dan diklat perlu } \\
\text { diprogram dan dilaksanakan secara berkala. } \\
\text { Dipercepat terbentuknya jabatan fungsional } \\
\text { konservator. Kampanye/promosi perlu dilakukan } \\
\text { berkala agar pelestarian naskah kuno dapat } \\
\text { diketahui oleh masyarakat. }\end{array}$ \\
\hline 4 & a. Sarana dan Prasarana & $\begin{array}{l}\text { Peralatan dan bahan konservasi masih impor, sistem } \\
\text { informasi preservasi belum ada, pemetaan koleksi } \\
\text { (survey kondisi) dilakukan tahun } 2013 \text { dan naskah }\end{array}$ \\
\hline
\end{tabular}




\begin{tabular}{|l|l|l|}
\hline \multicolumn{2}{|c|}{ Evaluasi Input } \\
\hline & & $\begin{array}{l}\text { yang dikonservasi adalah milik Perpustakaan } \\
\text { Nasional RI melalui hibah dan pembelian }\end{array}$ \\
\hline & b. Analisis Sarana dan Prasarana & $\begin{array}{l}\text { Sarana dan prasarana masih belum memadai. Sarana } \\
\text { dan prasarana yang masih diimport digunakan } \\
\text { dengan efisien agar tidak cepat rusak dan tepat } \\
\end{array}$ \\
& & $\begin{array}{l}\text { sesuai target kegiatan, sedangkan sistem informasi } \\
\text { pelestarian yang belum ada, hendaknya dapat } \\
\text { dipercepat proses pengadaannya agar percepatan } \\
\text { akses informasi pelestarian dan terbuka jaringan } \\
\text { informasi bagi lembaga Pemetaan koleksi } \\
\text { dilakukan secara berkala agar tingkat kerusakan } \\
\text { koleksi terpantau. }\end{array}$ \\
\hline 5 & a. Anggaran & $\begin{array}{l}\text { Anggaran yang ada belum sesuai dengan kebutuhan, } \\
\text { realisasi anggaran 10\% dari total anggaran. }\end{array}$ \\
\hline & b. Analisis Anggaran & $\begin{array}{l}\text { Anggaran harus ditambah agar dapat mengakomodir } \\
\text { kegiatan preservasi naskah kuno. }\end{array}$ \\
\hline
\end{tabular}

Berdasarkan wawancara dan hasil observasi dapat disimpulkan bahwa kegiatan preservasi fisik naskah kuno ini belum semua tersedia kebutuhannya yaitu dari mekanisme kerja preservasi, SDM, sarana dan prasarana dan anggaran. Kurangnya SDM, anggaran dan sarana prasarana di daerah menyebabkan penanganan preservasi naskah kuno dilimpahkan ke pusat. Di Perpustakaan Nasional RI kurangnya ketrampilan SDM, sarana dan prasarana serta anggaran yang terbatas menyebabkan tidak optimalnya kegiatan preservasi fisik naskah kuno. Dari hasil observasi diperoleh gambaran bahwa penerapan sistem informasi pelestarian lebih lambat dibandingkan sistem informasi lain di lingkungan Perpustakaan Nasional RI seperti KIN (Katalog Induk Nasional), KID (Katalog Induk Daerah). Sistem informasi pelestarian akan diaplikasikan pada tahun 2017, sesuai yang dikemukakan oleh Kepala Pusat Preservasi Bahan Pustaka "sistem informasi baru dikembangkan , tahun 2017 direncanakan sudah dapat diplikasikan.”

\section{Evaluasi Proses (Process)}

Evaluasi proses untuk membantu dalam mengimplemantasikan keputusan. Evaluasi proses ini terdiri dari implementasi rekomendasi IRT (International Reviewer Team), fungsi pembinaan pelestarian di tingkat pusat dan daerah, proses pelestarian naskah kuno, kerjasama, strategi dalam pelestarian naskah kuno, jadwal, penanggung jawab kegiatan, dan target kegiatan, hambatan yang dihadapi dalam kegiatan pelestarian fisik naskah kuno, lingkungan, kesiapsiagaan bencana, peralatan, serta penataan koleksi naskah kuno. Hasil temuan dan analisis evaluasi proses pada kegiatan preservasi fisik naskah kuno di Perpustakaan Nasional RI sebagai berikut: 
Tabel 5. Hasil Temuan dan Analisis Evaluasi Proses (Process)

\begin{tabular}{|c|c|c|}
\hline \multicolumn{3}{|c|}{ Evaluasi Proses } \\
\hline 1 & a. Penerapan rekomendasi IRT & Penerapan IRT 75\% sudah ditindaklanjuti \\
\hline & $\begin{array}{l}\text { b. Analisis penerapan rekomendasi } \\
\text { IRT }\end{array}$ & $\begin{array}{l}\text { Penerapan rekomendasi IRT menunjukkan bahwa } \\
\text { kebutuhan preservasi telah diakomodir oleh } \\
\text { Perpustakaan Nasional RI }\end{array}$ \\
\hline \multirow[t]{2}{*}{2} & $\begin{array}{l}\text { a. Fungsi pembinaan pelestarian } \\
\text { tingkat pusat dan daerah }\end{array}$ & $\begin{array}{l}\text { Fungsi pembinaan pelestarian di tingkat pusat dan } \\
\text { daerah belum maksimal }\end{array}$ \\
\hline & $\begin{array}{lcc}\text { b. Analisis } & \text { fungsi } & \text { pembinaan } \\
\text { pelestarian } & \text { tingkat } & \text { pusat dan } \\
\text { daerah } & & \\
\end{array}$ & $\begin{array}{l}\text { Perlu dilakukan penguatan fungsi pembinaan antara } \\
\text { pusat dan daerah dan mendorong peningkatan fungsi } \\
\text { pembinaan perpustakaan provinsi dan kabupaten/kota }\end{array}$ \\
\hline \multirow[t]{2}{*}{3} & a. Proses pelestarian naskah kuno & $\begin{array}{l}\text { Proses pelestarian naskah kuno dilakukan per tahapan } \\
\text { antara lain, survey kondisi, paginasi, pelepasan } \\
\text { selotape, deadifikasi, laminasi, sizing, pengeringan, } \\
\text { trimming, kontrol kualitas, penjilidan. }\end{array}$ \\
\hline & $\begin{array}{l}\text { b. Analisis Proses pelestarian } \\
\text { naskah kuno }\end{array}$ & $\begin{array}{l}\text { Proses pelestarian fisik naskah kuno sudah sesuai } \\
\text { dengan penanganan kerusakan naskah kuno. }\end{array}$ \\
\hline \multirow[t]{2}{*}{4} & a. Kerjasama & $\begin{array}{l}\text { Perpustakaan Nasional menjalin kerjasama dengan } \\
\text { lembaga di dalam negeri dan luar negeri }\end{array}$ \\
\hline & b. Analisis kerjasama & $\begin{array}{l}\text { Kerjasama yang dilakukan dengan lembaga lain dari } \\
\text { dalam dan luar negeri merupakan langkah yang tepat } \\
\text { dan perlu peningkatan kerjasama sebagai sarana } \\
\text { promosi pelestarian dan tukar menukar informasi } \\
\text { pelestarian }\end{array}$ \\
\hline \multirow[t]{2}{*}{5} & a. Strategi pelestarian naskah kuno & $\begin{array}{l}\text { Konservasi naskah sesuai standar dan kondisi naskah, } \\
\text { optimalisasi alih media, penggunaan naskah asli } \\
\text { dibatasi, penyimpanan naskah sesuai standar, staf } \\
\text { yang memiliki kompetensi yang melaksanakan } \\
\text { konservasi, melakukan kajian, transliterasi dan } \\
\text { terjemahan agar naskah asli awet }\end{array}$ \\
\hline & $\begin{array}{l}\text { b. Analisis Strategi pelestarian } \\
\text { naskah kuno }\end{array}$ & $\begin{array}{l}\text { Stategi pelestarian naskah kuno sudah sesuai dengan } \\
\text { kegiatan preservasi naskah kuno tetapi pelaksanaan } \\
\text { kegiatan belum semua sesuai dengan strategi. }\end{array}$ \\
\hline \multirow[t]{2}{*}{6} & $\begin{array}{l}\text { a. Jadwal, penanggungjawab, target } \\
\text { kegiatan }\end{array}$ & $\begin{array}{l}\text { Jadwal kegiatan selama } 3 \text { bulan yaitu bulan Juni, Juli, } \\
\text { dan Agustus. Penaggungjawab kegiatan adalah } \\
\text { Kepala Sub Bidang Perawatan dan Perbaikan Bahan } \\
\text { Pustaka. Target kegiatan 3-4 bulan. }\end{array}$ \\
\hline & $\begin{array}{l}\text { b. Analisis } \\
\text { penanggungjawab, } \\
\text { kegiatan }\end{array}$ & $\begin{array}{l}\text { Jadwal kegiatan sudah sesuai dengan rencana dan } \\
\text { penanggungjawab adalah orang orang yang } \\
\text { berkompeten dalam pelestarian naskah. Target yang } \\
\text { kegiatan sesuai dengan jadwal kegiatan } 3 \text { bulan tetapi } \\
\text { ada tenggat waktu sampai } 4 \text { bulan. }\end{array}$ \\
\hline \multirow[t]{2}{*}{7} & $\begin{array}{l}\text { a. Hambatan dalam kegiatan } \\
\text { pelestarian fisik naskah kuno }\end{array}$ & $\begin{array}{l}\text { Iklim indonesia yang salah satu penyebab kerusakan } \\
\text { naskah kuno, usia naskah kuno itu sendiri yang ratusan } \\
\text { tahun, sarana prasarana, SDM dan anggaran. }\end{array}$ \\
\hline & b. Analisis hambatan & $\begin{array}{l}\text { Masalah iklim dapat diatasi dengan penggunaan AC } \\
24 \text { jam, naskah kuno yang sudah tua dibatasi }\end{array}$ \\
\hline
\end{tabular}




\begin{tabular}{|c|c|c|}
\hline & & $\begin{array}{l}\text { penggunaannya, sarana dan prasarana, anggaran } \\
\text { ditambah, ketrampilan SDM ditingkatkan. }\end{array}$ \\
\hline \multirow[t]{2}{*}{8} & a. Lingkungan & $\begin{array}{l}\text { Lingkungan berpengaruh terhadap naskah kuno, di } \\
\text { Perpustakaan Nasional RI sudah berusaha } \\
\text { menciptakan lingkungan yang ideal bagi naskah kuno } \\
\text { tetapi ada beberapa hal yang belum memenuhi kriteria } \\
\text { diantaranya ruang penyimpanan sempit, AC tidak } \\
\text { menyala selama } 24 \text { jam, banyak buku lembab, alat } \\
\text { pengukur kelembaban rusak, pengecekan suhu dan } \\
\text { kelembaban terakhir tanggal } 03 \text { Agustus } 2015 \text {, staf } \\
\text { makan minum di ruangan. }\end{array}$ \\
\hline & b. Analisis lingkungan & $\begin{array}{l}\text { Ruangan sempit, AC tidak } 24 \text { jam, alat pengukur } \\
\text { kelembaban rusak, staf makan minum di ruangan } \\
\text { dapat menjadi penyebab kerusakan naskah kuno, } \\
\text { untuk itu ruangan yang sempit perlu diperlebar, AC } \\
\text { dinyalakan selama } 24 \text { jam, perlu perbaikan alat } \\
\text { pengukur kelembaban atau pengadaan baru, } \\
\text { pengecekan suhu dan kelembaban secara berkala, } \\
\text { perlu dibuatkan ruangan khusus untuk makan dan } \\
\text { minum pegawai. }\end{array}$ \\
\hline \multirow[t]{2}{*}{9} & a. Kesiapsiagaan Bencana & $\begin{array}{l}\text { Sudah ada Tim untuk kesiapsiagaan bencana, telah } \\
\text { dibuat pedoman menghadapi bencana, melakukan } \\
\text { sosialisasi, penyuluhan, workshop dan penyelamatan } \\
\text { koleksi pra dan pasca bencana }\end{array}$ \\
\hline & b. Analisis Kesiapsiagaan Bencana & $\begin{array}{l}\text { Perpustakaan Nasional RI sudah tepat dalam } \\
\text { menyiapkan kesiapsiagaan bencana }\end{array}$ \\
\hline \multirow[t]{2}{*}{10} & a. Peralatan & $\begin{array}{l}\text { Peralatan yang dimiliki sudah memenuhi untuk ruang } \\
\text { penyimpanan }\end{array}$ \\
\hline & b. Analisis peralatan & $\begin{array}{l}\begin{array}{l}\text { Perpustakaan Nasional RI sudah tepat dalam } \\
\text { menyediakan peralatan }\end{array} \\
\end{array}$ \\
\hline \multirow[t]{2}{*}{11} & a. Penataan koleksi & $\begin{array}{l}\text { Koleksi disusun agak berdesakan dan beberapa naskah } \\
\text { yang berukuran besar diletakkan di atas rak }\end{array}$ \\
\hline & b. Analisis penataan koleksi & $\begin{array}{l}\text { Penataan koleksi yang agak berdesakan dan naskah } \\
\text { yang diletakkan diatas rak dapat menyebabkan } \\
\text { kerusakan pada naskah kuno }\end{array}$ \\
\hline
\end{tabular}

Penerapan rekomendasi IRT terbentur pada laju kerusakan naskah kuno, iklim Indonesia yang tropis menjadi salah satu sebab cepatnya kerusakan naskah kuno dan kondisi ruang penyimpanan yang kurang memadai menambah kerusakan pada naskah kuno. Namun upaya pelestarian fisik naskah kuno tidak bisa menghambat kerusakan naskah kuno secara keseluruhan, solusinya adalah percepatan alih media dan deasidifikasi massal (mass deacidification). Kegiatan Preservasi fisik naskah kuno yang telah dilakukan di Perpustakaan nasional RI belum sesuai dengan tujuan dan strategi, seperti yang dituturkan oleh Kepala Pusat Preservasi Bahan Pustaka "belum semua sesuai dengan strategi karena terkait dengan tugas dan fungsi unit kerja lainnya." 
Proses pelestarian fisik naskah kuno ini berdampak positif terhadap koleksi yaitu koleksi diperbaiki dan menjadi terawat sehingga naskah terselamatkan fisik dan kandungan informasinya. Anggaran, sarana dan prasarana, SDM juga menjadi hambatan dalam pelestarian naskah kuno, seperti petikan wawancara dengan Kepala Sub Bidang Perawatan dan Perbaikan Bahan Pustaka berikut: "tentu saja memang yang pertama masalah anggaran, anggarannya ya memang sangat sangat sedikit, tentu saja sarana dan prasarana dan SDM nya juga yang tidak memadai."

Dari hasil observasi di lapangan hal-hal yang terkait dengan lingkungan penyimpanan dan penataan koleksi adalah :

\section{Ruang Penyimpanan}

Ruang penyimpanan sempit sehingga naskah yang tersimpan di rak berdesakan. Hasil pengecekan terakhir suhu dan kelembaban tanggal 3 Agustus 2015 , suhu $31^{\circ} \mathrm{C}$ dan kelembaban $65 \%$ dicek saat AC mati.

2. Pencahayaan

Pencahayaan di ruang penyimpanan naskah kuno di Perpustakaan Nasional RI berada di tengah, terhindar dari cahaya matahari secara langsung. Lampu tidak menggunakan lampu pijar tetapi menggunakan lampu yang sudah mengurangi radiasi.

3. Suhu

Suhu di ruang penyimpanan $24^{\circ} \mathrm{C}$. Suhu ini adalah ideal bagi tempat penyimpanan. Tetapi pemakaian AC tidak dinyalakan selama 24 jam. Fluktuasi temperatur yang tidak stabil akan menyebabkan kerusakan pada manuskrip.

4. Kelembaban

5. Penanganan terhadap serangga, jamur dan tikus

Penanganan terhadap serangga, jamur dan tikus dengan melakukan fumigasi. staf masih makan dan minum di ruang koleksi. Hal ini dapat menyebabkan datangnya serangga yang dapat merusak naskah.

6. Pembersihan koleksi secara berkala

Pembersihan koleksi dilakukan secara berkala oleh, Pustakawan, Konservator dan cleaning servis dengan pengawasan Pustakawan.

7. Fumigasi 
Fumigasi di Perpustakaan Nasional RI dilakukan setiap tahun akan tetapi karena banyaknya ruang koleksi yang ada di Perputakaan Nasional RI maka setiap tahun hanya 3 ruangan di lakukan fumigasi.

\section{Penataan Koleksi}

Koleksi naskah kuno ditata padat, hal ini dapat menyebabkan kerusakan pada naskah kuno. Sedangkan naskah kuno yang berukuran besar di letakkan di atas rak, hal ini dapat menyebabkan banyak debu di naskah kuno.

\section{Evaluasi Produk (Product)}

Evaluasi produk adalah suatu cara untuk mengukur keberhasilan program atau kegiatan. Pada evaluasi produk ini akan terlihat apakah kegiatan preservasi naskah kuno dapat dilanjutkan, dikembangkan atau dimodifikasi atau dihentikan. Hasil temuan dan analisis evaluasi produk pada kegiatan preservasi naskah kuno dapat dilihat pada tabel 4 sebagai berikut:

Tabel 4.Hasil Temuan dan Analisis Evaluasi Produk (Product)

\begin{tabular}{|c|c|c|}
\hline \multicolumn{3}{|c|}{ Evaluasi Produk (product) } \\
\hline 1. & a. Out Put Kegiatan & $\begin{array}{l}\text { Out put kegiatan preservasi fisik naskah kuno } \\
\text { adalah terkonservasinya naskah kuno } \\
\text { sebanyak } 10 \text { eksemplar, } 1 \text { eksemplar } 30 \\
\text { halaman }\end{array}$ \\
\hline & b. Analisis out put kegiatan & $\begin{array}{l}\text { Out put kegiatan sudah sesuai dengan target, } \\
\text { tetapi hasilnya belum signifikan dibandingkan } \\
\text { dengan jumlah kerusakan }\end{array}$ \\
\hline \multirow[t]{2}{*}{2} & a. Out come kegiatan & $\begin{array}{l}\text { Out come kegiatan ini adalah pemanfaatan } \\
\text { hasil preservasi fisik naskah kuno oleh } \\
\text { peneliti, dibuat kajian, diseminarkan, diajukan } \\
\text { sebagai Ingatan Kolektif Nasional (IKON) } \\
\text { dan diajukan sebagai warisan dunia melalui } \\
\text { MOW (Memory of the World) }\end{array}$ \\
\hline & b. Analisis out come kegiatan & $\begin{array}{l}\text { Out come kegiatan sudah baik, dilihat dari } \\
\text { pemanfaatannya. }\end{array}$ \\
\hline \multirow[t]{2}{*}{3} & a. Kesesuaian kegiatan dengan standar & $\begin{array}{l}\text { Kegiatan preservasi naskah kuno sudah } \\
\text { mengacu pada standar internasional : BS EN } \\
\text { 16882: } 2017 \text { : Conservation of Culture } \\
\text { Heritage Integrated Past Management }\end{array}$ \\
\hline & $\begin{array}{l}\text { b. Analisis kesesuaian kegiatan dengan } \\
\text { standar }\end{array}$ & $\begin{array}{l}\text { Kegiatan preservasi fisik naskah kuno telah } \\
\text { memenuhi standar internasional }\end{array}$ \\
\hline 4 & a. Keberlanjutan program & $\begin{array}{l}\text { Program/kegiatan akan dilanjutkan dengan } \\
\text { prioritas peningkatan konservasi dengan } \\
\text { target s.d. tahun } 202030 \% \text { dari jumlah naskah } \\
\text { sudah dilakukan restorasi dan konservasi }\end{array}$ \\
\hline
\end{tabular}




\begin{tabular}{|l|l|l|}
\hline b. Analisis keberlanjutan program & $\begin{array}{l}\text { Keberlanjutan program bisa dikatakan baik } \\
\text { karena kegiatan akan terus dilanjutkan dengan } \\
\text { peningkatan prioritas dan penetapan target } \\
\text { yang harus dicapai }\end{array}$ \\
\hline
\end{tabular}

Out put kegiatan ini adalah terkonservasinya naskah kuno sebanyak 10 eksemplar, 1 eksemplarnya berjumlah 30 halaman meskipun out put sudah sesuai dengan target kegiatan tetapi belum mengatasi secara signifikan kerusakan naskah kuno sebesar 56,21\%. Adapun out come dari kegiatan preservasi fisik naskah kuno ini sudah baik dilihat dari segi pemanfaatannya digunakan untuk kepentingan penelitian, ilmu pengetahuan, dan membanggakan bangsa Indonesia dengan adanya naskah yang diakui menjadi warisan dunia melalui MOW (Memory of the World). Kegiatan Preservasi fisik naskah kuno sudah sesuai dengan standar internasional, seperti yang diungkapkan oleh Kepala Pusat Preservasi Bahan pustaka sebagai berikut : "mengacu dan sesuai dengan standart internasional : BS EN 16882 : 2017 : Conservation of Culture Heritage Integrated Past Management."

Program/ kegiatan preservasi fisik naskah kuno di Perpustakaan Nasional RI akan terus dilanjutkan dengan prioritas untuk peningkatan jum lah konservasi dengan target 30 persen dari jumlah naskah yang sudah dikonservasi. Seperti yang dituturkan oleh Kepala Pusat Preservasi Bahan Pustaka: "prioritas untuk peningkatan jumlah konservasi target sampai dengan 202030 persen dari jumlah naskah sudah dilakukan restorasai dan konservasi.”

\section{KESIMPULAN}

Kesimpulan mengenai hasil penelitian pada kegiatan preservasi fisik naskah kuno di Perpustakaan Nasional RI adalah sebagai berikut:

1. Pada evaluasi konteks (context) yang terdiri dari tujuan kegiatan, konteks kegiatan, kebijakan dan evaluasi sudah dalam kategori baik. Tujuan kegiatan dan sasaran program sudah dikatakan ada relevansinya. Namun kegiatan preservasi naskah kuno ini belum tercapai sepenuhnya karena banyaknya naskah kuno yang belum dikonservasi. Jika dilihat dari segi kebutuhan untuk mencapai tujuan program masih banyak yang belum terpenuhi di antaranya SDM yang kompeten, anggaran, sarana dan prasarana, kebijakan dan standar nasional preservasi.

2. Pada evaluasi Masukan (input) yang terdiri dari pedoman/standar pelaksanaan kegiatan preservasi naskah kuno, mekanisme kerja preservasi, jumlah sumber daya manusia (SDM), 
sarana dan prasarana, dan anggaran sudah dalam kategori baik. Meskipun mekanisme kerja preservasi antara pusat dan daerah sudah ada tetapi pelaksanaannya di daerah tidak berjalan karena kurangnya SDM yang terampil, terbatasnya sarana dan prasarana serta anggaran yang belum memadai.

3. Evaluasi Proses (Process)

Evaluasi proses mencakup penerapan rekomendasi IRT, fungsi pembinaan pelestarian, proses pelestarian fisik naskah kuno, kerjasama, strategi pelestarian naskah kuno, jadwal kegiatan, penanggungjawab kegiatan, target kegiatan selesai, hambatan yang dihadapi dalam melakukan kegiatan pelestarian fisik naskah kuno, lingkungan, kesiapsiagaan bencana, peralatan dan penataan koleksi sudah dalam kategori baik. Namun terdapat kekurangan pada fungsi pembinaan pelestarian di tingkat pusat dan daerah masih belum maksimal, strategi pelestarian relevan dengan tujuan tetapi belum semua strategi tercapai, tempat penyimpanan yang sempit, AC tidak menyala selama 24 jam, banyak buku lembab, alat pengukur kelembaban rusak, penataan koleksi yang tidak memenuhi standar.

4. Evaluasi Produk (Product)

Evaluasi Produk ini mengukur keberhasilan program/kegiatan. Keberhasilan program/kegiatan terlihat dari out put, out come, kesesuaian kegiatan dengan standar dan keberlanjutan program. Dilihat dari segi out put telah sesuai dengan target kegiatan, walaupun belum mengatasi jumlah kerusakan naskah kuno secara signifikan. Dari segi out come, sudah dimanfaatkan untuk penelitian, mencari ilmu pengetahuan, dan naskah kuno menjadi kebanggaan bangsa Indonesia. Sedangkan kegiatan telah mengacu pada standar internasional. Keberlanjutan program diprioritaskan pada peningkatan konservasi dan pencapaian target sampai tahun 2020, dapat dikatakan bahwa kegiatan preservasi fisik naskah kuno yang telah dilakukan telah memenuhi target kegiatan.

\section{DAFTAR PUSTAKA}

Indonesia, Undang-undang 2007, Undang-undang Republik Indonesia no.43 tahun 2007 tentang Perpustakaan, Perpustakaan Nasional RI, Jakarta.

The IRT. (1991). Conservation and Preservation at the National Library of Indonesia, Jakarta Mishra, V.K. (2012) 'Indigenous method of manuscript conservation', Global Research Methodology Journal,issue 4. Diakses tanggal 22 Maret 2017. 
Bibliotech : Jurnal Ilmu Perpustakaan dan Informasi, 4 (1) 2019

http://ww w.grm grlaranya.com/Journals/4th\% 20issue/INDIGENOUS\%20METHO

D\%20OF\% 20MANUSCR IPT\%20CONSERVATION.pdf

Patidar, D. (2016). 'Indigenous material of preserving manuscripts in library', International Journal of Research in Library Science, 2(2),p. 183-187. Diakses tanggal 22 Maret 2017 http://ww w.ijrls.in/w p-content/uploads/2016/12/INDIGENOUS-MATERIAL-OFPRESERVING-1-1.pdf

Perpustakaan Nasional RI. (1999). Koleksi naskah pilihan Perpustakaan Nasional RI, editor, Sri Sumekar, et.al, hlm. 1-2.

Perpustakaan Nasional RI. (2012). Pedoman Pengelolaan Naskah Nusantara, penyusun, Dina Isyanti, et.al, hlm. 64-65.

Pusat Preservasi Bahan Pustaka. (2013). Laporan hasil pemetaan survei kondisi koleksi Perpustakaan Nasional RI tahun 2013.

Razak, M. (2004). Studi tentang Pelestarian Manuskrip Nusantara di Perpustakaan Nasional RI(tesis). Jakarta: Universitas Indonesia

Razak, M. (2009). Kebijakan teknis pelestarian bahan perpustakaan. Jakarta: Perpustakaan Nasional

Pusat Preservasi Bahan Pustaka. (2013). Laporan hasil pemetaan survei kondisi koleksi Perpustakaan Nasional RI. Jakarta: Perpustakaan Nasional

Soelistyowati, L. (2012). Pengelolaan Naskah Kuna oleh Perpustakaan Nasional RI: Prosiding. Seminar Naskah Kuna Nusantara. Perpustakaan Nasional RI. Jakarta. hlm.43-49.

Stufflebeam, D. (2003). The CIPP Model for Evaluation. Presentasi di Annual Conference of the Oregon Program Evaluator Network (OPEN). Diakses 26 Juli 2017

Teygeler, R. (2001). Preservation of Archive in Tropical climate, an Annoted Bibliography, International Council on Archive. Paris:The Haque

Wirayati, M.A. (2014). Pedoman teknis pelestarian bahan pustaka (konservasi kuratifbahan perpustakaan media kertas), Perpustakaan Nasional RI, Jakarta.

Wirayati, M.A. (2012). Pelestarian Manuskrip Lontar Bali (Studi kasus pelestarian manuskrip lontar di Museum Gedong Kirtya sebagai upaya melestarikan budaya Bali masa lampau (tesis). Bandung: Universitas Padjadjaran. 
Bibliotech : Jurnal Ilmu Perpustakaan dan Informasi, 4 (1) 2019

Woro, T.H. (2012). "Layanan Naskah Kuna di Perpustakaan Nasional RI Menuju Pusat Pernaskahan Nusantara”. Prosiding Seminar NaskahKuna Nusantara, Perpustakaan Nasional RI, Jakarta, hlm. 103-104 
Bibliotech : Jurnal Ilmu Perpustakaan dan Informasi, 4 (1) 2019 